\title{
A TRADUÇÃO E A INCONFIDÊNCIA MINEIRA ${ }^{1}$
}

\section{Irene Hirsch}

Conflitos entre as autoridades portuguesas e os brasileiros do século XVIII à época da reverberação das notícias da independência dos Estados Unidos da América são objeto de estudo de vários historiadores. A colônia de Portugal sofreu o impacto das novas idéias, que circularam na forma de discussões e livros, muitos dos quais eram traduções. Dois livros escritos em francês foram lidos pelos inconfidentes mineiros: a Histoire philosophique et politique, de Raynal, e o Recueil des loix constitutives des Colonies Angloises Confédérées sous la denomination d'Etats-Unis de la Amérique Septentrionale, uma tradução da Declaração da Independência dos Estados Unidos e das leis que antecederam a constituição estadunidense compiladas por Claude Ambrose Régnier. O livro de Régnier, elaborado para o público francês, chegou clandestinamente ao Brasil à época da Inconfidência Mineira. Neste artigo, examinarei esse documento, seguindo seu percurso dos Estados Unidos à Europa, e de lá para o Brasil, verificando como a filosofia política estadunidense chegou ao Brasil colonial, com a hipótese de que as traduções desempenharam um papel importante na propagação das idéias revolucionárias.

Como se sabe, a conspiração de Minas Gerais foi desmantelada em 1789, os acusados foram presos, e Joaquim José da Silva Xavier, o Tiradentes, a figura trágica central, foi executado em praça pública e os outros foram exilados ou morreram na prisão. Os estudiosos da Inconfidência basearam suas análises sobre as atividades e os bens dos acusados nos Autos da Devassa (ADIM), obra publicada em 1980, em 10 volumes. Ou seja, grande parte de nosso conhecimento sobre a conspiração é uma construção apoiada nos testemunhos e nas listas de bens confiscados dos insurgentes. Diferentes perspectivas procuraram explicar os motivos dos inconfidentes, e vários estudiosos descreveram-nos como sendo membros de uma elite de intelectuais idealistas que almejavam a emancipação política, enquanto que outros pesquisadores acreditavam

\footnotetext{
1 Uma versão desse trabalho foi apresentada no XVIII Congress of the International Comparative Literature Association, na Universidade Federal do Rio de Janeiro, em julho de 2007.
} 
tratar-se de colonizadores corruptos e endividados que queriam a insurreição para resolver suas dívidas pessoais (Mello e Souza, 2006: 362).

Não nos interessa discutir se o movimento foi uma divergência sócio-econômica ou uma conspiração que antecipou a Independência do Brasil, mas sim o fato de a base intelectual dos revolucionários ter sido informada pelas idéias do Iluminismo. Nos inquéritos dos Autos encontram-se provas concretas da circulação dessas idéias nos meios intelectuais da população. O exame das bibliotecas confiscadas revela que, apesar da ação da censura, elas estavam repletas de livros proibidos dos filósofos franceses do Iluminismo, como D’Alembert, Brissot, Buffon, Condorcet, Condillac, Diderot, Helvetius, La Mettrie, Mably, Marmontel, Montesquieu, Raynal, Rousseau (Villalta, 2006: 370).

A posse de bibliotecas particulares era privilégio de poucos no Brasil colônia, restrita aos letrados, muitos do quais estudaram na Europa e exerceram papéis importantes na trama. O acervo literário era diversificado em idiomas, e os conteúdos e as discussões se restringiam a um número limitado de pessoas, como comerciantes, professores, estudantes, funcionários públicos, soldados, livreiros, tipógrafos, escritores, membros de ordens religiosas secretas e padres.

Segundo Frieiro (1957), os revoltosos sentiam grande curiosidade pela América inglesa, embora pouco soubessem a seu respeito. Devido à sua vitoriosa sublevação anticolonial, a América inglesa era uma referência, e os líderes do levante, Jefferson, Washington e Franklin, eram famosos e respeitados. No entanto, quase nada vinha diretamente de lá e poucos sabiam ler inglês. Dos quase três milhões de habitantes da colônia, talvez nem mesmo cem tivessem alguma relação com o inglês: tudo vinha da França ou em francês. Um exemplo desse percurso, citado por Frieiro (p. 53), é o fato de o conjurado José Joaquim Maia ter escrito em francês suas cartas para Jefferson, quando este era embaixador na França.

Pesquisas sobre a presença de livros nas Minas Gerais da Inconfidência mostram que a biblioteca do bispo de Mariana, Dom Frei Domingos da Encarnação Pontével, com 412 títulos e 1.066 volumes, era a maior de todo o período colonial. No entanto, os livros iluministas se faziam presentes em maior número na biblioteca do cônego Luís Vieira da Silva, considerada a mais revolucionária. Desaparecida desde a revolta, tinha 241 títulos e 556 volumes. Outras bibliotecas importantes do período colonial foram as de Cláudio Manuel da Costa, com 99 títulos e 344 volumes; do padre Carlos Correia de Toledo, com 60 títulos e 105 volumes; do padre Manuel Rodrigues da Costa, com 59 
títulos e 207 volumes; do coronel José Resende Costa, com 20 títulos e 61 volumes; de Domingos Fernandes da Cruz, com sete títulos e 18 volumes; do coronel Inácio José de Alvarenga Peixoto, com quatro títulos e 18 volumes, e do coronel José Aires Gomes, com quatro títulos e quatro volumes (Villalta, 2006: 372-373).

O exame da biblioteca de um dos mais eruditos ativistas, a do cônego Luís Vieira da Silva, como descrita nos Autos dos bens seqüestrados, revela que mais da metade dos livros estavam escritos em latim, cerca de 90 em francês, mais de 30 em português, cinco ou seis em italiano, o mesmo número em espanhol e 24 em inglês (Frieiro, 1957:28). Entre os autores dos livros em francês encontravam-se importantes historiadores e filósofos ingleses em traduções, como Hume e Robertson: de Hume, havia a Histoire de la Maison d'Autriche, em seis volumes, e a Histoire de la Maison des Tudor, também em seis volumes. De Robertson, a Histoire d'Ecosse, em três volumes, a Histoire du règne de l'Empereur Charles-Quint, em seis, e a Histoire de l'Amerique, em quatro. Também em francês, em sua grande maioria, havia dicionários, tratados de física, geometria, astronomia, história natural, geografia, agricultura, artes militares, além de livros de medicina, filosofia, metafísica, lógica e os clássicos portugueses e pensadores da Antiguidade Clássica. Outras traduções encontradas na biblioteca do cônego foram as obras de Metastasio e de Aurelio Bertola de Giorgi, em francês, e a Ars poetica de Horácio, em português, traduzida por Francisco José Freire (Frieiro, 1957:41-43). Observa-se, portanto, que a biblioteca do cônego era constituída em grande parte por traduções, que informavam o universo cultural dos poetas árcades e mentores da revolução. Infelizmente, no entanto, a biblioteca desapareceu por completo.

Outro importante documento desaparecido é a tradução de A riqueza das nações, de Adam Smith, que supostamente foi feita e comentada por Cláudio Manoel da Costa, um dos líderes da revolta e poetas dos mais importantes, que também traduziu peças de Metastasio (Maxwell, 1995: 147; Rouanet, 2006: 330). Joaquim Norberto, o famoso historiador do século XIX, comenta que Cláudio Manoel da Costa foi o primeiro escritor português a discutir a nova ciência política e que "o manuscrito foi apreendido com outro inédito seu e teve o sumiço que o fisco real achou conveniente dar-lhe” (Silva, 1911: 68).

\section{O livro de cabeceira de Tiradentes}

O Recueil des loix constitutives des Colonies Angloises Confédérées sous la denomination d'Etats-Unis de la Amérique Septentrionale, considerado o livro de 
cabeceira de Tiradentes, é uma tradução do inglês para o francês feita por Claude Ambrose Régnier, que foi lida por vários inconfidentes. Trata-se de uma compilação das constituições de seis dos 13 estados confederados e da declaração de independência, redigida por Thomas Jefferson, sendo, portanto, um documento baseado nos princípios do Iluminismo transformados em leis, com as idéias desenvolvidas por Locke, Montesquieu, Rousseau e Adam Smith. Esses documentos fundadores foram impressos clandestinamente em 1778, provavelmente em Paris, apesar de, na capa, ser feita menção à Suíça, e apenas dois exemplares terem chegado ao Brasil colonial, sendo que só um sobreviveu e hoje é uma das raridades expostas no Museu da Inconfidência em Ouro Preto. Uma tradução parcial para o português do texto em francês foi feita por Tarquínio J. B. de Oliveira e publicada em 1981 nos Autos da Devassa. Uma lista completa dos documentos da coleção, conforme referido na “Tábua das Matérias”, é:

- Censo das Treze Colônias - 1775

- Ato da Independência, de 04/07/1776

- Ato da Confederação, de 04/10/1776

- Ato do Congresso Geral reunido em 15/05/1776, que ordena às Colônias Unidas estabeleceram novas formas de governo

- Diploma de doutor enviado ao General Washington pela Universidade de Cambridge, Nova Inglaterra, de 03/04/1776

- Ato da Navegação das Colônias Unidas, decretado pelo Congresso Continental em 06/04/1776

- Instrução do Congresso Continental aos armadores, decretada em $10 / 04 / 1776$

- Fórmula das comissões aos armadores dada pelo Congresso Geral a 22/04/1776

- Constituições

- Pensilvânia, de 15/07/1776

- Nova Jersey, de 02/07/1776

- Delaware, de 11/09/1776

- Maryland, de 14/08/1776

- Decreto de Maryland, dispensando de juramento ao rei da Grã-Bretanha os empregados na administração, 15/05/1776

- Virgínia, de 01/06/1776 
- Carolina Meridional, de 26/03/1776

- Adesão da Cidade de Georgetown à nova forma de governo da Carolina Meridional, em 06/05/1776

- Outra constituição da Carolina Meridional, de 03/02/1777

- Juramento da província da Baía de Massachussetts

- Instrução ditada pela cidade Boston ao Congresso Geral

Por se tratarem de documentos clandestinos, a autoria da publicação também é cercada de hipóteses. Segundo Tarquínio J. B. de Oliveira, Claude Ambrose Régnier, o compilador e tradutor para o francês, foi um advogado famoso em Nancy, França, eleito deputado durante a Revolução Francesa, que teve de se refugiar com o advento do terror (ADIM, 1981). No entanto, Elise Marienstras e Naomi Wulf (1999) afirmam que a autoria das traduções do livro publicado em 1778 é controversa; que Gilbert Chinard a atribui a um misterioso e ousado Régnier, mas que outros a atribuem a La Rochefoucauld. De acordo com o site da Gallica, ${ }^{2}$ a tradução de Régnier é uma das três edições da constituição estadunidense que Franklin teria pedido a La Rochefoucauld para traduzir para o francês, sendo que o próprio Franklin o teria ajudado nessa tarefa. Além disso, teria sido publicada na Filadélfia e não na Suíça, e vendida clandestinamente em Paris. Devido às circunstâncias obscuras que envolvem os documentos, pode-se concluir apenas que se tratava de uma obra censurada, destinada a ser material de propaganda política na França. Como então chegou às mãos dos inconfidentes em Ouro Preto, Minas Gerais, e se tornou leitura diária de Tiradentes? Tarquínio informa sobre a chegada dos dois exemplares do Recueil a Minas Gerais em 1788: o primeiro, um presente de José Álvares Maciel a Tiradentes, no Rio de Janeiro, no mês de julho, sendo o exemplar que hoje se encontra no Museu da Inconfidência em Ouro Preto; e o segundo, trazido em outubro pelo Dr. José Pereira Ribeiro, um advogado de Mariana, que teria servido de estudos a Tomás Antônio Gonzaga e Cláudio Manuel da Costa, os redatores das leis mineiras. Esse último exemplar teria sido provavelmente destruído às vésperas do início da repressão em 1789. Tarquínio menciona a existência de pequenas e poucas notas dispersas pelo volume, que supõe serem de Tiradentes, e sustenta a hipótese de que o alferes utilizava um sistema revolucionário de propaganda através de seu livro: simulando necessitar da tradução de

\footnotetext{
${ }^{2}$ Gallica, Bibliothèque Nationale de France. Em http://gallica.bnf.fr/ark:/12148/bpt6k80090d.notice. Acesso em 04 nov. 2008.
} 
alguns trechos da obra, deixava-a com o tradutor a quem pedira o favor, para que, por meio da leitura feita, entrasse ele em contato com o teor da obra (ADIM, 1981: 23).

A coletânea em francês, um volume apenso aos Autos, no entanto, não ficou em Minas Gerais. Em 1860 a documentação sobre a Inconfidência Mineira foi doada à Biblioteca de Florianópolis por Melo Morais, antigo diretor da Biblioteca Nacional, para onde foi expedida em 1978. O Recueil voltou à guarda do governo do estado de Minas Gerais no século seguinte, em abril de 1984, quando o governador de Minas Gerais, Tancredo Neves, solicitou ao governador de Santa Catarina, Espiridião Amin, que devolvesse o documento que pertencera a Joaquim José da Silva Xavier. A petição foi considerada legítima, e em 21 de abril de 1984 foi assinado um documento transferindo o livro, em uma cerimônia oficial.

\section{A agenda dos inconfidentes e o Iluminismo}

O movimento conjurado estava imbuído da filosofia iluminista, principalmente no que tange à questão da contraposição metrópole versus colônia, aliada ao discurso das leis e direitos de uma nação livre e independente. As idéias de igualdade social, direito à liberdade, garantia do uso e desfrute da terra pelos colonos e, em especial, a proposta de um movimento em Minas Gerais, estado que considerava um levante contra o monarca algo justificado, da “vontade dos povos”, negando o princípio legitimador do poder régio, equiparava-se à crítica ao absolutismo, presente em filósofos como Locke, Rousseau e Voltaire.

Em A devassa da Devassa, Maxwell aponta semelhanças entre as constituições dos Estados da União Americana, a obra do abade Raynal e a agenda da Inconfidência: a capital da nova república seria instalada em São João Del Rei; uma casa da moeda seria criada; o câmbio sofreria controle; o Distrito Diamantino se veria livre da legislação restritiva; o minério de ferro seria explorado; manufaturas implantadas; uma universidade seria fundada; para cada cidade haveria um parlamento, subordinado a um principal na capital; após três anos sob o governo de Gonzaga, anualmente realizar-seiam eleições (Maxwell, 1978: 151-152).

No centro dos eventos revolucionários mineiros está situado o livro com a tradução da declaração da independência e das leis estadunidenses. Assim como há controvérsias em relação ao personagem central, o Tiradentes, também há diferentes opiniões sobre a propriedade do exemplar. Há uma verdadeira luta historiográfica em torno do alferes. Durante o Segundo Reinado, quando o país era governado por 
familiares da rainha Maria, que ordenara a execução, o tema Inconfidência Mineira era embaraçoso. Poucos historiadores estrangeiros e alguns literatos ousaram exaltar o personagem. Mais tarde, a luta entre a memória de Pedro I, promovida pelo governo, e a de Tiradentes, símbolo dos republicanos, tornou-se emblemática dos entraves entre a Monarquia e a República. Dois anos após o Manifesto Republicano, em 1872, foi proposta a construção de um monumento a Tiradentes no Rio de Janeiro. Joaquim Norberto de Souza Silva, autor da História da Conjuração Mineira e descobridor dos documentos dos Autos da Devassa, discordou da idéia, argumentando que Tiradentes fora uma figura secundária, sendo então acusado de estar a serviço da monarquia e tentar denegrir a imagem do herói (Carvalho, 1990: 61-62).

A despeito da oposição de historiadores como Joaquim Norberto e Varnhagen, e dos monarquistas defensores de D. Pedro I, que achavam que o martírio conferia méritos que Tiradentes não tinha, que ele era um personagem iletrado e insignificante, o mito foi se alargando e ele foi identificado com Cristo e apresentado como o herói republicano, num misto de fervor cívico e religioso. Apesar de ser um símbolo ambíguo, Tiradentes tornou-se um herói nacional.

A mesma ambigüidade envolve a tradução das leis estadunidenses. Rafael de Freitas e Souza argumenta que é do interesse da historiografia regional mineira conferir a Tiradentes o perfil de intelectual e, dessa forma, transformar o livro, a prova do crime, em testemunho de grandeza (Souza, 2004: 179-180). A historiografia oficial teria utilizado o livro para dar um verniz intelectual a Tiradentes, para glorificá-lo como líder, um homem corajoso de ação e das letras, e, seguindo essa linha de raciocínio, considerar a Inconfidência Mineira um movimento precursor da República. Sugere que o chamado "livro de Tiradentes" pode não ter pertencido ao alferes, pois não há evidências historiográficas da autoria das notas manuscritas às margens do livro. Poderia ter pertencido aos teóricos do movimento, como Tomás Antonio Gonzaga ou Cláudio Manoel da Costa.

A tradução para o português do Recueil e o texto de Tarquínio e Matias, publicados nos Autos da Devassa, em 1980, sob o patrocínio da Câmara dos Deputados e do governo de Minas Gerais, são reveladores do interesse de se oficializar a versão que exalta a história e engrandece os protagonistas da Inconfidência Mineira. A cerimônia oficial de entrega do documento às autoridades mineiras, em 1984, reitera essa intenção de glorificar os revoltosos como mártires da libertação, já que se trata de um documento que, nas palavras de Régnier, é “um dos mais belos monumentos da 
sabedoria humana” (ADIM, 1981) e que, segundo Tarquínio, conferia "ao alferes estatura e dimensão até agora ignoradas pela historiografia brasileira” (ibidem).

O Récueil des loix constitutives des colonies angloises, confederées sous la denominacion d'Etats-Unis de l'Amerique Setentrionale atualmente está exposto numa vitrine no Museu da Inconfidência, ao lado de Obras, de Cláudio Manoel da Costa, 1768, e de Marilia de Dirceu, de Tomaz Antônio Gonzaga, 1789. A edição clandestina de 1788 do Recueil está exposta como raridade bibliográfica, com a indicação de "que serviu como referência aos inconfidentes e foi apreendida com um deles, provavelmente Tiradentes”. Seja um concerto laudatório ao proto-mártir da independência ou um veículo de transmissão de idéias revolucionárias, o Recueil é um documento traduzido fundador, que aponta para a importância das traduções na difusão de idéias que dão origem a movimentos políticos.

\section{Referências}

Autos da Devassa da Inconfidência Mineira - ADIM (1981) v.3. 2ª ed. Brasília: Câmara dos Deputados; Belo Horizonte: Imprensa Oficial de Minas Gerais.

CARVALHO, José Murilo de (1990) A formação das almas: o imaginário da república no Brasil. São Paulo: Companhia das Letras.

FREITAS E SOUZA, Rafael de (2004) "Combate nas Luzes: a recepção e leitura do Recueil pelos inconfidentes mineiros”. Dissertação da Faculdade de Filosofia e Ciências Humanas da UFMG.

FRIEIRO, Eduardo (1957) O diabo na livraria do cônego. Belo Horizonte: Itatiaia.

FURTADO, João Pinto (2002) O manto de Penélope. São Paulo: Companhia das Letras.

MARIENSTRAS, Elise \& WULF, Naomi (1999) "French translations and reception of the Declaration of Independence”. http://chnm.gmu.edu/declaration/marien.html Acesso em 04 nov. 2008.

MAXWELL, Kenneth (1995) A devassa da Devassa - A Inconfidência Mineira - Brasil e Portugal: 1750 - 1808, $3^{\text {a }}$ ed. Trad. João Maia. São Paulo: Paz e Terra.

MELLO E SOUZA, Laura (2006) “Tensões sociais em Minas na segunda metade do século XVIII”. Adauto Novaes (org.) Tempo e história. $3^{\mathrm{a}}$ ed., 347-366. São Paulo: Companhia das Letras. 
MORAES, Rubens Borba de (1979) Livros e bibliotecas no Brasil Colonial. Rio de Janeiro/São Paulo: Livros Técnicos e Científicos Secretaria da Cultura, Ciência e Tecnologia do Estado de São Paulo.

ROUANET, Sergio Paulo (2006) “As Minas iluminadas, a ilustração e a Inconfidência”. Adauto Novaes (org.) Tempo e história, 3ª ed., 329-346. São Paulo: Companhia das Letras.

SOUZA E SILVA, Joaquim Norberto de (1911). História da Conjuração Mineira. Rio de Janeiro: Garnier.

VILLALTA, Luiz Carlos (2006) “O diabo na livraria dos Inconfidentes”. Adauto Novaes (org.) Tempo e história, $3^{\mathrm{a}}$ ed., 367-395. São Paulo: Companhia das Letras. 